\title{
Strategic adoption of logistics and supply chain management
}

\begin{tabular}{|r|l|}
\hline Journal: & International Journal of Operations and Production Management \\
\hline Manuscript ID & IJOPM-05-2016-0258.R3 \\
\hline Manuscript Type: & Research Paper \\
\hline Keywords: & Logistics, Supply chain management, Practitioner perspectives, Strategic \\
\hline \multicolumn{2}{|c}{} \\
\hline
\end{tabular}




\section{Strategic adoption of logistics and supply chain management}

\section{Structured Abstract}

Purpose: This paper develops a thorough understanding of the adoption of logistics and supply chain management in practice, particularly at a strategic level, through an investigation of a four perspectives taxonomy of the relationship between logistics and supply chain management.

Design/methodology/approach: Based on a comprehensive literature review three specific research questions are proposed. The empirical work addresses these questions and comprised three phases: focused interviews, a questionnaire survey and focus groups.

Findings: The findings provide a usage profile of the four perspectives and indicate a divergence between the understanding and adoption of logistics and SCM principles and concepts at a strategic level in firms. The findings also identify critical success factors and inhibitors to success in addressing this divergence.

Research limitations/implications: The insights generated using the authors' methodologically pluralist research design could be built upon to include case studies, grounded theory and action research. Replicating the research in other geographical areas could facilitate international comparisons.

Practical implications: The findings allow practitioners to compare their perspectives on the relationship between logistics and supply chain management with those of their peers. The critical success factors and inhibitors to success provide a rational basis for realising the strategic potential of logistics and supply chain management in practice.

Originality/value: New insights are generated into practitioner perspectives vis-à-vis logistics versus supply chain management. A fresh understanding of those factors which drive and hinder the adoption of strategic SCM is also developed and presented. 
Keywords: logistics, supply chain management, practitioner perspectives

Paper classification: Research Paper

\section{Introduction}

A plethora of logistics and supply chain management (SCM) definitions have been developed over the years evidencing different emphases and approaches among practitioners across different industrial sectors, geographical areas and functional backgrounds (Stock and Boyer, 2009). In addition, a range of often quite complex logistics and SCM language and terminology has evolved concomitantly (Croom et al., 2000; Tan, 2001; Cousins et al., 2006). Given that there are many bodies of literature associated with the field (e.g. operations, transport, purchasing and supply, operational research) this should not come as a major surprise (Zinn and Goldsby, 2014).

There is less debate and a higher level of consensus in the literature about the meaning of the word 'logistics', however regarding SCM Lambert (2004) noted there is a great deal of confusion regarding exactly what SCM involves. Kotzab et al. (2011, p. 233) stated that "there is a dearth of evidence in relation to the extent to which SCM - as defined in the academic literature - is implemented or even understood in practice". As some have noted, logistics and SCM academics maintain angst about finding a relevant and unified theory of SCM (Mentzer et al., 2001, 2004; Sweeney, 2011).

Larson and Halldórsson (2004) set out a taxonomy of four possible perspectives on logistics versus SCM - traditionalist, unionist, intersectionist and re-labeling - based on a survey of logistics educators from North and South America, Europe and Asia. Surprisingly, little research has been carried out since then to explore the extent to which elements of this taxonomy are important to practitioners and have been adopted in practice. Understanding these issues is paramount for academics to provide research-led solutions to various issues in this applied discipline. 
This paper addresses this tension and gap to develop a more thorough understanding of logistics and SCM in practice with specific reference to the taxonomy. It does so with a particular emphasis on the extent to which logistics and SCM principles and concepts are adopted at a strategic level by firms, as well as with a view to identifying the critical success factors and inhibitors to success in this context.

Following this introduction, the literature review provides an overview of the evolution of logistics and SCM, as well as of the relationship between them based largely on the four perspectives taxonomy of Larson and Halldórsson (2004), discusses the strategic role of logistics and SCM in this context, and develops our three research questions. The three-phase methodology employed to generate insights into these questions is presented next, followed by an explanation of the empirical research in each phase and the main findings. We then discuss key insights generated by the research and finally conclude the paper with the main implications for theory and practice and directions for future research.

\section{Literature review}

\subsection{Evolution and definitions of logistics and SCM}

The concept of logistics has existed for centuries with most early references to the concept being found primarily in military applications. However, over time the application of logistics has moved into the mainstream business arena (Bowersox, 1969; Bartels, 1982; Stock, 1997). Numerous definitions of logistics have been proposed and most refer to the physical movement and storage of materials.

The US Council of Supply Chain Management Professionals (CSCMP, 2016) is the world's largest practitioner association for logistics and SCM with over 9,000 members across the globe and hence it definitions for these topics have currency with practitioners. CSCMP defines logistics as:

...that part of Supply Chain Management that plans, implements, and controls the efficient, effective forward and reverse flow and storage of goods, services and related information between the point of origin and the point of consumption in order to meet customers' requirements. 
The CSCMP definition of logistics indicates that it is a principal antecedent to SCM and that logistics is a subset of SCM. We adopt this definition of logistics for use in this paper to ensure consistency in our approach.

The term 'supply chain management' or SCM was originally introduced by management consultants in the early 1980s (Oliver and Webber, 1982) and many definitions of SCM have been developed and reviewed over the last three decades. Bechtel and Jayaram (1997) presented a comprehensive review of definitions of both 'supply chain' and 'supply chain management' which appeared between the early 1980s and the mid 1990s. Mentzer et al. (2001) provide an overview of the more important of these definitions and, based on their analysis, propose a definition of their own. Stock and Bowyer (2009) examined 173 definitions of SCM that have appeared in the literature "to determine important components of an integrated definition of SCM" (p. 690). The CSCMP definition (2016) which follows is widely cited in the literature:

Supply chain management encompasses the planning and management of all activities involved in sourcing and procurement, conversion, and all logistics management activities. Importantly, it also includes coordination and collaboration with channel partners, which can be suppliers, intermediaries, third-party service providers, and customers. In essence, SCM integrates supply and demand management within and across companies.

This definition incorporates the main elements of contemporary SCM thinking and we likewise adopt this working definition for this paper. Central to this thinking is the shift away from traditionally fragmented supply chain architectures towards more integrated approaches (see, for example: Christopher and Towill, 2000; Carter et al, 2015). Managing supply chain processes in a more integrated manner requires that performance measurement is carried out more holistically (see, for example, Burgess et al., 2006; Sweeney et al., 2015). Several scholars have endeavoured to place this evolving SCM thinking in an historical context (Masters and Pohlen, 1994; Christopher and Towill, 2000; Stank et al., 2011). The adoption of SCM thinking involves a move away from the functional stovepipe or silo approach to more seamless configurations. This transition from fragmented to more integrated 
approaches has been facilitated by a range of information and communications technology (ICT) tools that have developed over the years (Zhang et al., 2011).

Thus, while logistics and SCM are often considered as primarily operational activities, contemporary approaches in the literature have a strong focus on what are regarded as long-term strategic issues, with much research into logistics and SCM now being published in the strategic management literature (Grimm et al., 2015). This concept of strategic logistics and SCM is concerned with leveraging the supply chain as a source of competitive advantage; however, the extent in the literature to which this shift towards a more strategic focus has been reflected in practice remains unclear (Larson et al., 2007; Halldórsson et al., 2008; Kotzab et al., 2011; Stank et al., 2011).

\subsection{The relationship between logistics and SCM}

Lummus et al. (2001, p. 427) stated that, "What is not always clear is how logistics differs from ...supply chain management". The work of Larson and Halldórsson (2004) provided useful insights into this issue with their taxonomy of four conceptual perspectives on logistics versus SCM. Larson et al. (2007) note that this construct was originally derived in 1999 based on a review of the literature and some informal consultation with practitioners. Figure 1 shows a schematic representation of the four perspectives taxonomy.

INSERT FIGURE 1 ABOUT HERE.

The traditionalist perspective positions SCM within logistics: that is, SCM is one part or subset of logistics. Larson and Halldórsson (2004) noted that firms adopting this perspective might create 'SCM analyst' or similar positions with a view to broadening the scope of logistics analysis. The re-labelling perspective does no more than rename logistics; what was logistics becomes SCM. In practice, the logistics director and his/her function acquire new titles but with no change in job description or responsibilities. The unionist perspective treats logistics as a part or a subset of SCM, i.e. logistics is completely subsumed by SCM. The CSCMP definitions of logistics and SCM above represent an example of this school of thought. Finally, the intersectionist perspective is described as follows by Larson and Halldórsson (2004, p. 21): 
The intersectionist concept suggests SCM is not the union of logistics, marketing, operations management, purchasing and other functional areas. Rather, it includes strategic, integrative elements from all of these disciplines.

One simple example from the logistics outsourcing area is used to illustrate this perspective: "hiring a third-party logistics (3PL) provider is a strategic decision, while picking and packing in the warehouse are tactical" (2004, p. 21). In essence, the intersectionist perspective views $\mathrm{SCM}$ as primarily strategic, with the focus of logistics on more tactical or operational issues.

\subsection{Academic adoption of four perspectives taxonomy}

Larson and Halldórsson (2004) reported on a survey of logistics/SCM experts regarding these perspectives that involved a survey sent to 208 logistics academics in early 2000. Based on that study Larson and Halldórsson concluded that "the empirical results support the four perspectives model of logistics versus SCM" (2004, p. 25). Their analysis, based on the use of a clustering algorithm, categorised the majority of respondents $(51 \%$ as re-labellers, with much smaller numbers of unionists $(22 \%)$, traditionalists (16\%) and intersectionists $(7 \%)$.

Larson et al. (2007) built on this work by carrying out an survey of US-based practitioners. This involved sending a questionnaire survey to 600 supply chain professionals, all of whom were members of CSCMP. They found that unionist was the most popular perspective (47\%), followed by intersectionist $(28 \%)$, traditionalist $(19 \%)$ and re-labelling (6\%). These findings point to significant differences between academic and practitioner perspectives of the taxonomy.

Halldórsson et al. (2008) then compared the results of Larson et al. (2007) with the situation in Scandinavia. Insights into the latter were obtained using a questionnaire survey sent to 91 supply chain professionals in Denmark, Norway and Sweden, all members of CSCMP; 23 usable responses were received (response rate of 28.4\%). The popularity of the four perspectives was similar among Scandinavian and American practitioners (52\% unionist, 26\% intersectionist, 13\% traditionalist and 9\% re-labelling). 
The studies cited above suggest that the four perspectives taxonomy finds certain resonance among academics. Several recent text books have used the taxonomy to explain the relationship between logistics and SCM (Grant, 2012; Mangan et al. 2012) which suggests that it has become part of the "canon of approved modes of thinking about business" (Westbrook and New, 2004, p. 284). This view is reinforced by scholars across a range of logistics and SCM domains adopting one of the four perspectives, the unionist approach, as a point of departure for their research. For example, Green et al. (2008) used it to develop a logistics performance model, Tatham and Kovács (2010) recognised it in the context of humanitarian logistics, Sandberg and Abrahamsson (2010) used it in investigating the role of senior management in SCM, and Evangelista et al. (2012) adopted it in their work on technology use by third party logistics service providers (3PLs).

\subsection{Strategic logistics and SCM}

It is clear that as the fields of logistics and SCM have evolved, they have assumed a more strategic orientation. Relating this to the Larson and Halldórsson (2004) taxonomy, the re-labelling and traditionalist perspectives are quite narrow and function-oriented, while the unionist and intersectionist perspectives are broader and more strategic in nature. That logistics and SCM has assumed a more strategic perspective is confirmed by the recent work of Grimm et al. (2015). Based on their review of all articles in five top management journals between 2004 and 2013 that present research pertaining to supply chains, they note that:

Most logistics/SCM researchers are aware of related research in operations management. However, there is also a large and growing literature on SCM topics within the field of strategic management (p. 405).

Porter (1996) observed that firm performance depends on both operational effectiveness and strategic differentiation. The role of logistics and SCM in the former has long been recognised and is essentially about performing similar activities better than rival firms perform them. The latter is concerned with deciding which activities to perform so that a firm clearly differentiates itself from its rivals. Park (2007, p.90) set out the strategic dimension of SCM very succinctly: 
Against a background of increasingly rapid and, at times, discontinuous change we need to consider the broader value of SCM in creating a differentiated business model that determines competitive advantage in the judgement of customers.

Thus, it is increasingly recognised that logistics and SCM activities have a key role at a strategic level in firms in the creation of competitive advantage. In line with this, the more widespread adoption of the unionist and intersectionist perspectives of Larson and Halldórsson (2004) indicates that a key trend in the evolution of logistics and $\mathrm{SCM}$ in academia has involved the development of a more strategic orientation. However, the limited number of empirical studies relating to the adoption of these two perspectives can only suggest that they may be more widely accepted among practitioners than the other two. But, while academics provide guidance for practice based on the taxonomy - primarily the unionist and intersectionist perspectives - are either really understood and/or appropriated by practitioners? If not, are solutions to important and real-world problems by academics in our applied discipline really useful to practice? We reiterate that knowing the practitioner's viewpoints is paramount for academics to provide appropriate solutions and guidance for practice to properly operate.

\subsection{Development of research questions (RQs)}

As noted in section 2.1 a plethora of logistics and SCM definitions, as well as a range of often quite complex terminology have been developed over the years (Stock and Boyer, 2009). With reference to SCM specifically, Mentzer et al. (2001) refer to confusion, ambiguity and a need to examine the phenomenon more closely to define the term and concept. In a similar vein and as noted earlier, Lambert (2004) noted there is a great deal of confusion regarding exactly what SCM involves. Croom et al. (2000, p. 68) argued that despite the existence of SCM since the early 1980s, "conceptually the management of supply chains is not particularly well understood" and went on to highlight the necessity for clear definitional constructs. Burgess et al. (2006, p. 704) observed that, "For the term SCM there appears to be little consensus on its definition". Kathawala and Abdou (2003, p. 141) concluded that SCM "has 
been poorly defined and there is a high degree of variability in people's minds about what is meant".

More recently and as noted in section 1, Kotzab et al. (2011, p. 233) stated that "there is a dearth of evidence in relation to the extent to which SCM - as defined in the academic literature - is implemented or even understood in practice". There is less debate and a higher level of consensus in the literature about the meaning of the word logistics. Nonetheless, given that one of the principal antecedents of SCM is the field of logistics, this paper explores practitioner perspectives in relation to both (i.e. logistics and SCM) with particular reference to the relationship between the two terms. We therefore set out our first research question as follows.

\section{RQ1. How do practitioners view logistics and SCM, as well as the relationship between them?}

The four perspectives taxonomy of Larson and Halldórsson (2004) may have entered the canon of logistics and SCM concepts but there has been little research into the prevalence of the various perspectives in practice beyond the specific work in the American and Scandinavian contexts discussed above. The work described in this paper addresses this gap in the literature and we therefore set out our second research question as follows.

\section{RQ2. What is the profile of practice in terms of the Larson and Halldórsson (2004) four perspectives taxonomy?}

There is evidence of a shift towards a more strategic orientation in the logistics and SCM literature. For example, the limited evidence that does exist specifically in relation to the four perspectives taxonomy points to increasing adoption of the more integrative and strategic orientations. Thus, we need to generate empirical evidence to validate this shift. Insights developed from RQ1 and RQ2 will add to this body of evidence by providing a profile of practitioner perspectives. However, there is a need to go further by developing deeper and richer insights into the issues under investigation. 
Given that logistics and SCM have a potentially pivotal strategic role to play, and that the supply chain itself is becoming a key potential source of strategic leverage, it is not surprising that there is significant evidence that effective implementation of the principles and concepts can result in improvements in the performance of firms (see, for example: Elmuti et al., 2008; Ellinger et al., 2011). However, there is also evidence of a divergence between theory and practice, particularly in relation to the practical implementation of logistics and SCM concepts and principles at a strategic level in firms. Carter and Narasimhan (1994) suggested that the incorporation of SCM into the overall business planning process was not widely practiced. However, Storey et al. (2006) asserted that "while there is an emerging body of theory which ostensibly offers a relatively coherent and compelling prescriptive narrative, predominant practice is at considerable odds with this conceptualisation" (p. 755). More recently, Halldórsson et al. (2015) suggest that SCM needs theorizing across its many horizontal and vertical layers, and that a dialogue with other disciplines is necessary to advance SCM theory.

In short, there is evidence to suggest that there are substantial gaps between theory and practice (Storey et al., 2006). Stank et al. (2011) make a similar point when they state that "unfortunately, few companies have yet to take advantage of the stakeholder value opportunity presented through supply chain activities" (p. 941). These arguments raise important questions concerning the real impact of logistics and SCM principles and concepts at a strategic level in firms and hence provide the primary motivation for this study.

Further, there is also a view that there is a need for normative guidance from academia in relation to logistics and SCM adoption. The divergence between theory and practice that is a feature of the literature suggests that this guidance needs to have a strong focus on understanding the drivers and inhibitors of the adoption of logistics and SCM principles and concepts at a strategic level in firms. We therefore set out our third research question as follows.

RQ3. What are the critical success factors and/or inhibitors to success in putting logistics and SCM principles and concepts into practice at a strategic level? 
In essence, RQ1 and RQ2 aim to provide a profile of practitioner perspectives. Whilst this is interesting in its own right, it is the drivers of adoption and the attendant barriers that are of primary interest in the context of the current study. Thus, identification of critical success factors (CSFs) and attendant inhibitors to success (i.e. RQ3) represents the core of the authors' empirical research, building on the context and background provided by RQ1 and RQ2.

\section{Research design}

The nature of the three RQs required that a methodologically pluralist research design be used. This also responds to the many calls in the literature for the generation of fresh insights into phenomena associated with logistics and SCM through the use of research designs that incorporate strong qualitative components (Mangan et al., 2004; Seuring, 2005; Stock et al., 2010) thus facilitating the generation of deeper and richer insights into phenomena than would be possible using exclusively quantitative methodologies that view supply chains through primarily positivist prisms.

The empirical research was carried out in Ireland. This represents an appropriate geographical context given the open nature of its trade-dependent island economy, as well as the high levels of inward investment and consequent prevalence of European hubs in key sectors such as life sciences and electronics. A range of appropriate methods were used as part of an overall integrated research design, with a strong emphasis on the need for the various methods to complement each other as integral elements of a cohesive overall strategy. Specifically, the research design comprised three main phases as shown in Figure 2.

\section{INSERT FIGURE 2 AROUND HERE}

The development of insights into the RQs required that the overall research design incorporate both exploratory and explanatory dimensions. Exploratory research seeks to find out what is happening, particularly in little-understood situations, as well as seeking new insights and assessing phenomena in a new light. Given the paucity of research into some of the phenomena under investigation, the exploratory part of the current research aims to paint a picture of the main relevant challenges and issues. 
This is particularly relevant in the context of generating a profile of practitioner perspectives as required by RQ1 and RQ2.

The exploratory part of the research comprised two phases. To generate some initial insights into RQ1, the authors carried out a series of focused (i.e. semi-structured) interviews during phase I of the research. This largely inductive and qualitative work involved interviewing managers from two third party logistics providers (3PLs)/distributors, two retailers and two manufacturers. It is to a large extent a replication and update of the work of Lummus et al. (2001).

Phases II and III of the research were also designed to facilitate the development of additional insights into RQ1. RQ2 required the development of a profile of practice in terms of the four perspectives model of Larson and Halldórsson (2004) in phase II. A questionnaire survey provided an efficient means of achieving this objective. As part of a wider questionnaire survey on logistics and SCM understanding and adoption distributed to over 1,000 supply chain professionals across all main sectors, the authors included a number of carefully worded questions aimed at facilitating the development of such a profile. The relevant questions related to: respondent understanding of logistics and SCM, as well as of the relationship between them; and, current and planned logistics/SCM improvement initiatives. Thus, phase II of the work uses a classic hypothetico-deductive approach and is largely quantitative in nature. As with RQ1, the other phases in the research were designed to generate further insights into issues directly associated with RQ2.

The explanatory part of the research in phase III used three focus groups comprising 28 practitioners in total. This technique allows fresh insights into the key issues to be generated as a result of participants probing each other's reasons for adopting particular perspectives. Given the centrality of RQ3 in this research, the authors have carefully incorporated relevant elements into phases I and II to provide some initial exploration of the key issues. Phase III is a largely qualitative piece of work which builds directly on this initial exploration to inductively develop insights into the drivers and barriers influencing the adoption of logistics and SCM at a strategic level in firms (i.e. thus responding to RQ3). 
The development of the research design shown in Figure 2 was also guided by the suggestions for future research made by the authors of the limited number of previous empirical investigations into the four perspectives taxonomy. Larson and Halldórsson (2004) recommended that future research should use qualitative approaches, with "indepth interviews" and "focus group discussions" (p. 28) specifically proposed as two potentially fruitful methods of generating fresh insights. Larson et al. (2007) suggested that the functional (i.e. logistics) and geographical (i.e. USA) focus of their study "while limiting our ability to generalize the survey results, gives rise to future research opportunities" (p. 20). Our study shifts the geographical focus to Ireland, thereby facilitating cross-country comparison (including comparison with the Scandinavian situation reported in Halldórsson et al., 2008).

Halldórsson et al. (2008) also elaborated on the issue of functional focus by pointing out that their study's reliance on the membership of CSCMP as a sampling frame was somewhat problematical given that CSCMP's history "suggests that its members are functionally focused on logistics, as opposed to purchasing or operations" (p. 138). Our study acknowledges this point by capturing the views of supply chain professionals from a range of functional backgrounds across all three of its constituent phases.

Finally, use of the CSCMP's membership as a sampling frame also means that the previous surveys were "tilted toward larger, private-sector firms" (Halldórsson et al., 2008, p. 138). The questionnaire survey in phase III of the current study used a stratified random sampling approach with stratification based on NACE industry sectors. This is aimed at ensuring that the sample is truly representative of the population of firms under investigation.

\section{Findings}

\subsection{Phase I: focused interviews}

The interview sample comprised two 3PLs/distributors, two retailers and two manufacturers. The chosen sample of companies handles a wide variety of product groups thus enabling the authors to generate a breadth of perspectives. In each case, the informants were senior managers with responsibility for logistics and SCM issues. 
Each was sent a copy of the following three questions to consider for their upcoming interview:

- How do you define logistics?

- How do you define supply chain?

- How are these areas (i.e. logistics and supply chain) related?

This phase of the research then involved carrying out focused (i.e. semi-structured) interviews with each respondent. A key objective of all interviews was development of an understanding of informants' perspectives on the relationship between logistics and SCM. Interviews were recorded and transcribed, with analysis of each using a form of content analysis that interrogated the data for references to the four perspectives model.

Table 1 indicates which of the four perspectives of Larson and Halldórsson (2004) best describes the view of each respondent. Where a respondent articulated an approach which comprised elements of more than one perspective, these are listed in order. For example, the perspective of Manufacturer 1 is primarily unionist in that he regarded "logistics as a subset of SCM" but there are elements of the intersectionist view in his statement that "logistics is the execution phase" of SCM. The perspective is, therefore, classified as "unionist/intersectionist".

\section{INSERT TABLE 1 AROUND HERE}

As can be seen in Table 2, the predominant approach observed is a combination of unionist and intersectionist. The exceptions are Manufacturer 2 and Retailer 1. The former - classified as purely unionist - appeared to have a good knowledge of SCM principles and concepts but stated that he regarded them as "theoretical" and "aspirational". The latter, who expressed the view that logistics and SCM are "one and the same thing", also appeared to have a good knowledge of SCM principles and concepts but regarded them as being of "little or no relevance" as a consequence of the firm's dominant position in the supply chain. 
INSERT TABLE 2 AROUND HERE

As per the research design, the phase I interviews allowed the authors to generate some initial insights into all RQs, in particular RQ1. The data collected during phases II and III allowed the authors to then generate deeper and richer insights, thus building on these initial phase I findings.

\subsection{Phase II: questionnaire survey}

As noted in section 3, a carefully designed web-based questionnaire was distributed to supply chain professionals in 1,010 firms. The sampling design used stratified random sampling with stratification based on industry sectors using NACE (Nomenclature générale des Activités économiques dans les Communautés Européennes) codes. 125 usable responses were received from across the 21 sectors consulted, representing a response rate of $12.3 \%$. In order to detect non-response bias, a number of nonrespondents were contacted and there was no evidence of any significant nonresponse bias. A number of late respondents were also compared to earlier respondents - on the basis that late respondents are likely to share certain characteristics with non-respondents (see section 3.8.8) - and again no evidence of any significant differences was found.

The first part of the survey comprised three open questions:

- What is meant by the term "logistics"?

- What is meant by the term "supply chain"?

- What is meant by the term "supply chain management (SCM)"?

Usable responses were received from the majority of respondents with a wide variety of words and phrases used to define the three terms. An initial content analysis of the responses to these questions was carried out by looking at the frequency of occurrence of particular words and phrases. The 25 most frequently occurring words shown in the word clouds in Figures 3 and 4 provide some insights into how respondents define the terms "logistics" and "supply chain management (SCM)". 


\section{INSERT FIGURE 3 AROUND HERE}

In relation to defining "logistics", the concepts of "movement" and "transport" of "materials" through the chain (i.e. from "(point of) origin" to "(point of) consumption"), as well as "storage/warehousing", are prevalent. Other words associated specifically with the "move" and "store" links in the supply chain (e.g. "distribution" and "inventory/stock") also appear. Two words commonly used by respondents are "effective" and "efficient" indicating that respondents regard logistics as being fundamentally concerned with the effective and efficient movement and storage of product.

\section{INSERT FIGURE 4 AROUND HERE}

Interestingly, the most frequently used word in defining SCM is "customer" indicating a strong "pull" orientation among respondents. The importance of the management of "flows" - in particular the management of "information" - is also recognised by respondents. The other key words used reflect the importance of suppliers and their management to the achievement of customer service (the words "supplier" and "service" respectively). The word "right" reflects the classic "seven rights" approach to defining logistics/SCM (Lambert and Stock, 1992; Mangan et al. 2012). Many of the words/phrases are identical to those used to define "logistics". This perhaps suggests an element of re-labelling.

Responses to the core question (i.e. "What is the relationship between SCM and logistics?") were provided by all respondents with the great majority (87.8\%) regarding logistics as part of SCM (i.e. the unionist perspective - see Figure 5). It should be noted that the intersectionist perspective was not offered as a specific option as it is difficult to capture simply in a single-sentence format. However, the small number of respondents who answered "other" provided further explanation which in each case put them in the intersectionist category.

\section{INSERT FIGURE 5 AROUND HERE}


The data were analysed to test for any differences based on: (i) sector; (ii) firm size; (iii) firm ownership; and (iv) respondent background. The $\chi^{2}$ test indicates that no or only slightly significant differences exist by sector, size and ownership. Figure 6 shows the data based on the professional background of respondents with the $\chi^{2}$ test suggesting that highly significant differences exist (VS).

\section{INSERT FIGURE 6 AROUND HERE}

Two specific questions were asked of respondents in an effort to generate insights into their firms' logistics/SCM strategic orientation. These related to the types of logistics/supply chain improvement initiatives that: (i) have been implemented during the last two years; and, (ii) are planned for the next two years. A summary of the responses to the former question is shown in Figure 7.

\section{INSERT FIGURE 7 AROUND HERE}

The most common response referred to investment in technology of some kind. For example, one response referred to implementation of an enterprise resource planning (ERP) system linked to customers and suppliers. Many responses had a primarily operational focus, often with a menu of options set out. Several responses in this category specifically alluded to the implementation of lean thinking in firms' operations. Many respondents referred to improvements that were primarily organisational in nature. Such responses often made specific reference to the architecture of the supply chain and the outsourcing of supply chain activities. One respondent, for example, spoke of "consolidation of shipments via one logistics provider". Some responses were more strategic than operational in focus, typically mentioning the need for "end-to-end" or "chain-wide" approaches. One such response referred to a "complete review of the supply chain". Other respondents did no more than state targets that had been achieved (e.g. "33\% reduction in stock holding"), while a small number had a specific focus on human resource issues and the people dimension (e.g. "improved cross-functional communications"). Some responses fell into more than a single category. 
Figure 8 shows the types of logistics/supply chain improvement initiatives planned in respondents' firms in the next two years. As with initiatives undertaken in the last two years, technology-oriented improvements are the most common. Specific examples mentioned by respondents included retail point-of-sale systems and voice-based technologies. Interestingly, there is evidence of a somewhat stronger focus on strategic and integrative improvements in future planning than in earlier initiatives. Initiatives aimed at operational and organisational improvement are again common. These included the introduction of new planning tools and the identification of alternative distribution channels. A small number of firms in the sample cited initiatives aimed specifically at generating improvements in environmental sustainability. As with previously implemented initiatives, some responses fell into more than a single category.

\section{INSERT FIGURE 8 AROUND HERE}

The key message from these findings is that a minority of both previous and planned supply chain improvement initiatives could be regarded as strategic or integrative in nature. This is despite the fact that the great majority of respondents provided definitions of SCM that were primarily strategic in nature and which fell into the broader and more strategic of the Larson and Halldórsson (2004) perspectives.

The findings during the exploratory phases of the research then needed to be explored in more detail and this was achieved using a series of focus groups with key informants in phase III.

\subsection{Phase III: focus groups}

In phase III three focus groups were conducted and comprised 28 supply chain professionals in total: twelve in focus group 1 (FG1); ten in focus group 2 (FG2); and, six in focus group 3 (FG3). Participants were from a range of sectors including food and beverage manufacturing, life sciences, electronics, 3PL, software and the public sector. All firms represented had a strong international dimension in their supply chains. 
The focus group sessions were designed to provide insights into all RQs, although particular attention was paid to the core RQ3 - i.e. what are the critical success factors and/or inhibitors to success in putting logistics and SCM principles and concepts into practice at a strategic level? The sessions were facilitated and moderated by a carefully chosen independent person. Each session was recorded and transcribed. Analysis of the transcripts used a similar approach to that used in the analysis of the focused interview transcripts in phase I - i.e. content analysis using the four perspectives model as its basis. In addition, the concepts of data and theory saturation informed the authors' analytical process (Onwueghuzie et al., 2009; Bryman and Bell, 2003). The analysis revealed five interesting findings.

First, there was a strong emphasis across all three focus groups, and among adherents to each of the four perspectives, on the need to turn logistics and SCM understanding into practical action, particularly at a strategic level. In general, the discussions suggested that while a high level of understanding of logistics and SCM concepts and principles existed there was significant room for improvement in terms of how to implement this thinking. The public sector participants contended that the traditionalist perspectives of their organizations represented an obstacle to the implementation of improved logistics and supply chain processes. Nonetheless, in the context of RQ3 there was general agreement that the existence of a particular perspective is in itself neither a facilitator nor a barrier to improvement. The discussion did reinforce the authors' contention that the development of a deeper understanding of these factors is important.

Second, the predominant perspectives adopted by participants across all focus group sessions were unionist and intersectionist. The deliberations of FG3 provide an illustration of this. One participant from the 3PL sector expressly referred to logistics as a "microcosm" of the wider SCM domain, with its focus on balancing cost and service objectives. This reflects a strong unionist perspective. Other FG3 participants also broadly agreed that, in addition to the materials and inventory management focus of logistics, the management of money and information flows were important in the wider SCM context. The intersectionist view found expression in the context of FG3's discussion on the respective roles of strategic and tactical SCM. The participant holding the most senior position (from a US-headquartered life sciences company), 
and the only participant with responsibility across most elements of his firm's supply chain asserted that SCM is first and foremost a strategic issue. He further stated that if not treated as such - i.e. if the focus is mainly tactical or operational - then this inevitably results in "fire-fighting" and crisis management throughout the supply chain. These sentiments found strong resonance among all other participants. However, all FG3 participants expressed a degree of frustration with their lack of involvement in the more strategic dimension of the subject and many acknowledged that their roles had a narrow logistics focus (i.e. rather than the broader role associated with SCM). The group's conclusion was that SCM needs to be highly proactive with a strong focus on strategic issues. Logistics can then focus on the execution of this strategy. This thinking is wholly in line with the intersectionist perspective. Similar unionist and intersectionist thinking was evident in the discussions of FG1 and FG2. These findings clearly highlight the importance of distinguishing between strategic and tactical foci in strategic SCM adoption, and suggests that this in itself is a driver and/or inhibitor of effective implementation.

Third, holders of other perspectives (i.e. traditionalist and re-labelling) tended not to defend their positions when challenged by other participants. As noted earlier, the public sector representatives in all three groups indicated that their organizations could perhaps best be categorized as traditionalist but were awake to the many obstacles to improvement that this perspective implies. One FG2 participant from the food industry indicated that his firm had recently changed the titles of the logistics function and its staff to include the term "supply chain" but that there had been no change in the practices adopted by the firm. He demonstrated a certain cynicism about this classic re-labelling and certainly made no effort to justify it. Several other FG2 participants shared similar experiences that they had previously been part of. These findings speak to the need for higher levels of recognition at a senior level of the key strategic role of SCM.

Fourth, despite the apparent lack of prevalence of the re-labelling perspective among participants, some of the group discussions indicated that this approach was more common than first appearances might have suggested. This was manifested in the extent to which key activities were considered by participants to be part of both logistics and SCM. For example, several FG1 participants highlighted the role that 
both logistics and SCM need to play in optimising cost and service performance. FG2 participants generally agreed that managing the movement or flow of resources throughout the supply chain was a key activity in both logistics and SCM. The discussion also resulted in the general consensus that management of the key flows provides the basis for effective supply chain control. However, there was less consensus on whether this was primarily a logistics or SCM activity. The view of one participant that "what matters is that it gets done; it doesn't really matter how we designate it" suggests that re-labelling of functions and positions may happen from time to time without any real process change necessarily taking place.

Finally, all FG3 participants agreed that it is the customer who drives the supply chain. One participant explained how excellence in customer service was a source of strategic differentiation in his business. Other participants could, to greater or lesser extents, provide similar examples from their organisations. In this context, the need for a life cycle (or "cradle-to-grave") perspective was subscribed to by the four participants from manufacturing organisations. The point is that SCM needs to be a consideration from initial product concept through to product development and introduction and through to the end of a product's life cycle. One participant used the example of postponement to illustrate this point - i.e. products have to be designed to enable a postponement or late configuration strategy to be adopted. In this context, products are designed to meet a customer requirement in the market place and these products need to be supplied to customers efficiently and effectively.

\section{Discussion}

RQ1 asked how practitioners view logistics and SCM, as well as the relationship between them. The six interviews carried out by the authors during phase I of the empirical research supported the four perspectives approach of Larson and Halldórsson (2004). All six informants identified clearly with one or more of these perspectives and no alternative perspectives emerged from the interviews. A similar situation was evident among the 28 participants across the three focus groups in phase III. Furthermore, all survey respondents in phase II were able to position their views in one of the four categories. That no other perspective emerged from any of the three phases of the empirical research supports the validity of the original construct. Another interesting feature that emerged from the qualitative work in phases I and III 
was that perspectives most identified with by informants often differed from practice in their own firms. This appeared to be the case with Manufacturer 2 and Retailer 1 in phase I (see Section 4.1) and with several of the participants in FG3 in phase III. As noted in Section 4.3, many FG3 participants were able to recognise the strategic importance of SCM - a key feature of the intersectionist perspective - but felt a certain frustration that this was not the established practice. This supports what New (1997, p. 16) referred to as the "normative tension" between the is and the ought where "the rhetoric of managerial folklore tells managers to feel that they should take a broad, integrative approach and "manage the whole chain"" in line with the current authors' working definition of SCM but where the practical reality is somewhat different.

RQ2 sought to develop a profile of practice in terms of the four perspectives model of Larson and Halldórsson (2004). The data in Figure 5 provide such a profile in the context of Ireland. As noted in Section 4.2, the great majority of respondents thought of themselves as unionists. Table 3 shows the data from the surveys of Larson et al. (2007) in the US, Halldórsson et al. (2008) in Scandinavia and that of the current authors.

\section{INSERT TABLE 3 ABOUT HERE}

In each case, the unionist perspective is the most common. The authors of the earlier studies attributed this to the general move in this direction among professional bodies and academics, with Halldórsson et al. (2008, p 132) stating that:

The popularity of unionism is of little surprise, given the theoretical tilt toward this perspective among professional groups, such as CSCMP, and SCM scholars, like Lambert et al. (1998) and Mentzer et al. (2001).

Findings from the more qualitative components of the current study (i.e. phases I and III) suggest similar reasons for the high prevalence of the unionist perspective amongst respondents to the Irish study. However, it is likely that the real prevalence of the intersectionist perspective in Ireland is higher than indicated by the current study. As noted in sction 4.2 (above), this is a product of the relative difficulty in 
providing an easily intelligible intersectionist single-sentence option to the closed question on this topic. Furthermore, Larson et al. (2007) confirmed that practitioners often have multiple perspectives vis-à-vis logistics versus SCM and that the broader and more strategic perspectives (i.e. unionist and intersectionist) are strongly favoured over the narrower and more logistics-oriented perspectives (i.e. traditionalist and relabelling). The qualitative work in phases I and III supports these contentions. One final observation in relation to profiling perspectives is that Larson et al. (2007) found significant differences between respondents from different sectors (i.e. manufacturing, wholesale/retail and logistics). In contrast, the current study found no significant differences between respondents from different sectors based on the NACE codes.

Turning to RQ3, the empirical research suggests that there is widespread understanding - at least on a conceptual level - of the principles and concepts of logistics and integrated SCM, as well as of their potential application as a source of competitive differentiation. This is borne out by the alignment of most interviewees in phase I with the broader and more strategic perspectives (i.e. unionist and intersectionist) rather than the narrower and more logistics-oriented perspectives (i.e. traditionalist and re-labelling) of Larson and Halldórsson (2004). The phase II survey data reinforced this view but also revealed that a small minority of past and planned supply chain improvement initiatives could be regarded as strategic or genuinely integrative in line with the authors' working definition of SCM. As noted in Section 4.3 , the focus group discussions suggested that while a high level of understanding of logistics and SCM concepts and principles appears to exist, there is significant room for improvement in terms of how to implement this thinking. Thus, the findings across all phases of the empirical research indicate that while the logic of the strategic logistics and SCM narrative is widely understood, there appear to be some difficulties in translating this logic into practice. This suggests that an "understanding into action conundrum" or an "implementation deficit disorder" exists. This is in line with the comment of Storey et al. (2006) that:

while there is an emerging body of theory which ostensibly offers a relatively coherent and compelling prescriptive narrative, predominant practice is at considerable odds with this conceptualisation (p. 755). 
It also supports the findings of a recent study by Jin et al. which revealed that awareness of the strategic potential of SCM practices "is insufficient to mobilize resources and mitigate resistance to collaboration" (2013, p. 205). The research in phase III suggested some possible explanations for the phenomena under investigation. In particular, it highlighted some of the critical success factors (CSFs) and/or inhibitors to success in implementing logistics and SCM principles and concepts in practice, thus providing some more specific insights into RQ3.

Research across all three phases of the research identified a number of CSFs and/or inhibitors to successful SCM adoption, specifically at a strategic level. These barriers and drivers were also particularly prevalent during the various focus group discussions in phase III. Table 4 shows how both the exploratory and explanatory phases of the empirical research informed the identification of four CSFs and/or inhibitors to success. In each case, the findings from at least one component of the exploratory research (i.e. the phase I focused interviews and/or the phase II questionnaire survey) and at least one component of the exploratory research (i.e. the three focus group sessions in phase III) was used to arrive at the kernel of our response to RQ3. Table 4 also shows the implicit requirements on the part of management in addressing each issue in question. These are based on a reflection by the authors on our empirical findings through the prism of key issues that emerged during the literature review. Some of the key sources from the extant literature upon which this reflection is based are also indicated in Table 4. The following sections discuss these issues in some detail with a particular emphasis on how the divergence between theory and practice can be bridged. In each case, specific reference is made to the sources mentioned in Table 4 to clearly demonstrate how the empirical findings from this research relate to relevant material from the authors' literature review.

\section{INSERT TABLE 4 ABOUT HERE}

First, there is a need to clearly understand the distinction between strategic and tactical foci in logistics and SCM practice. The deliberations of FG3 in phase III (see section 4.3) were particularly instructive in this regard - i.e. general agreement in relation to the strategic role of logistics and SCM combined with a degree of frustration about lack of involvement in strategic decision making. This lack of 
strategic focus is also evident from the phase II questionnaire survey findings regarding past and planned improvement initiatives. In line with the foregoing, the role of leadership and senior management in developing appropriate supply chain strategies was emphasised throughout the focus group discussions (particularly in FG1). These findings suggest that the adoption of a more strategic approach to logistics and SCM is a critical success factor. This might appear self-evident but the corollary of this is that the adoption of a primarily operational or tactical approach is an inhibitor to success - the authors' empirical evidence suggests that this is the case in many firms. This is in line with some of the widely cited papers in the literature on the subject of integrated logistics and SCM (Simchi-Levi and Kaminsky, 2003; van Hoek and Harrison, 2004). The cultural shift towards a more strategic focus requires that logistics and SCM be regarded as senior management concerns (Fawcett et al., 2011). This in turn requires the adoption of a pro-active approach to investing in supply chain capability in advance of the requirement and the adoption of appropriate supply chain performance measurement systems (Sweeney et al., 2008).

Second, the literature is replete with calls for the development of consensus definitions of SCM to facilitate a common understanding of the concept, particularly at a strategic level (Mentzer et al., 2001; Stock and Boyer, 2009). In the phase I focused interviews there was a degree of divergence among the six key informants from different parts of the supply chain (i.e. manufacturing, 3PL/distribution and retail) in relation to what the supply chain and SCM entails. The phase II survey data and the phase III focus group discussions (particularly FG2) reinforced this point. This suggests that the development of common definitions and understandings between supply chain partners would appear to be a critical success factor; the corollary of this is that a lack of definitional consistency and common understandings may be inhibitors. Thus, the authors' empirical research supports the calls in the literature for the development of consensus definitions. The core SCM concept of higher levels of inter-firm integration and the concomitant building of customer/supplier partnerships are likely to promote such a development (Jin et al., 2013). The adoption of some of the principles of supply chain learning (SCL) - based on firm-to-firm exchange of knowledge - also has a potential role in this context (Bessant et al., 2003). 
Third, phases I and III of the authors' empirical work highlighted the need for a strong customer focus and an associated pull-orientation. This supports previous longstanding literature on integrating marketing and logistics activities, e.g. Bartels (1982), Stock (2002) and Grant (2010). For example, FG1 was strongly of the view that any worthwhile approach to putting the principles and concepts of logistics and SCM into practice at a strategic level has to be driven by a clear understanding of evolving customer requirements, which is in turn dependent on the way in which relationships with customers are managed. Current and future customer requirements define the parameters (or "set the spec") for the design and management of supply chains (Korpela et al., 2001). In any case, the concept that logistics and SCM are driven by customer demand is clear from the literature, and that a strong focus on existing and emerging customer requirements is a critical success factor is evident from the authors' empirical research. The core SCM concepts of higher levels of integration with customers and the attendant building of strategic partnership-based relationship models are important in the move from 'push' to 'pull' supply chain configurations (see, for example, Jin et al., 2013).

Fourth, the relative emphasis of firms on the hard-wiring (e.g. technology, information, and measurement systems) and soft-wiring (i.e. people) of their supply chains emerged as another critical success factor. This is clearly illustrated in relation to the past and planned improvement initiatives of survey respondents in phase II. As shown in Figure 7, just 3\% of the responses received referred specifically to a people dimension (i.e. the soft-wiring) in past improvement initiatives. A similar situation exists in relation to planned future initiatives, where technology-oriented improvements (i.e. the hard-wiring) are easily the most common. Furthermore, the role of employee involvement and buy-in to the supply chain change process was emphasised throughout the discussions of FG1 and FG3. There also was broad agreement that these people-related issues should be at the core of any worthwhile attempt at putting logistics and SCM principles and concepts into practice at a strategic level (Trautrims et al., 2012). The relative neglect of the people dimension (i.e. the soft-wiring) would appear to be a barrier to success, i.e. the critical success factor is the appropriate incorporation of soft-wiring considerations into supply chain decision making. This is in line with Storey et al. (2006) and Tokar (2010), and is perhaps most succinctly articulated by Fawcett et al. (2008, p. 35) who stated that: 
People are the key bridge to successful collaborative innovation and should therefore not be overlooked as companies invest in supply chain enablers such as technology, information, and measurement systems.

This raises issues in relation to the development of appropriate supply chain knowledge and skills. In this regard, education and training have a key role to play in shaping the orientation of managers and addressing these soft-wiring considerations.

\section{Conclusions}

This study adopted a methodologically pluralist approach using focused interviews, a questionnaire survey, and focus groups, and allowed fresh insights into each of the three RQs generated thus building our understanding of the phenomena under investigation. In terms of implications for researchers, the expansion of the research design to incorporate a range of appropriate methodologies (including case studies, action research and grounded theory) has the potential to build upon the explanatory dimension of the authors' work. This is specifically the case in relation to RQ3 where the use of in-depth case study analysis has particular potential to generate deeper and richer insights. This type of analysis would allow the incorporation of specific measures to evaluate the relative importance of the various drivers and barriers. In terms of RQ1 and RQ2, the current research does provide a profile in relation to practitioner perspectives on logistics vis-à-vis SCM in Ireland at a particular point in time. It would be useful for longitudinal studies to be put into place so that a barometer of progress over time could be developed. Notwithstanding the appropriateness of Ireland as the context of this research (see section 3) and the international scope and experience of most of the key informants, expanding the research into other geographical areas would facilitate further international comparisons. This is line with the suggestion of Halldórsson et al. (2008).

In terms of implications for practitioners, the findings allow logistics and supply chain professionals to compare their perspectives on the relationship between logistics and SCM with those of their peers. The CSFs and inhibitors to success derived by the authors provide a rational basis - i.e. one informed by empirical research - for addressing the 'understanding into action conundrum' referred to in section 5. This is 
important if the strategic potential of logistics and SCM is to be realised in practice. This need for academia to provide normative guidance to practitioners was referred to in section 2.5. Upon reflection of the work to date, there is a need for new theories that facilitate the development of clearer and deeper insights into the myriad interconnected phenomena at play in today's complex global logistics and supply chain architectures. As noted by Fawcett and Waller (2011) in their editorial in the Journal of Business Logistics:

Our world is chaotic and dynamic. Good theory is needed to: (1) resolve the many pressing challenges that confront us daily; as well as to, (2) take advantage of the tremendous opportunities that continue to emerge with the advent of new technology, adjustments in government policy, and adaptations in social thought (p. 3).

The recent work of Carter et al. (2015) and Halldórsson et al. (2015) regarding theories for the supply chain and SCM, and of Sweeney et al. (2015) regarding SCM adoption in practice, make useful contributions. The development of more robust theoretical foundations would allow scholars to provide more meaningful normative guidance to practitioners, thus building on the current authors' contribution. In this context, we concur with Skjoett-Larsen (1999) in his statement that "nothing is more practical than a good theory" (p. 51).

\section{REFERENCES}

- Bartels, R. (1982), 'Marketing and Distribution are not Separate,' International Journal of Physical Distribution \& Logistics Management, 12(3), 3-10.

- Bechtel, C. and Jayaram, J. (1997), 'Supply chain management: a strategic perspective', The International Journal of Logistics Management, 8(1), 15-34.

- Bessant, J., Kaplinsky, R. and Lamming, R. (2003), Putting Supply Chain Learning into Practice', International Journal of Operations \& Production Management, 23(2), 167-184.

- Bowersox, D.J. (1969), 'Physical Distribution Development, Current Status, and Potential,' Journal of Marketing, 33(January), 63-70. 
- Burgess, K., Singh, P.K. and Koroglu, R. (2006), 'Supply chain management: a structured literature review and implications for future research', International Journal of Operations \& Production Management, 26(7), 703-729.

- Bryman, A. and Bell, E. (2003), Business Research Methods, Oxford: Oxford University Press.

- Carter, C.R., Rogers, D.S., \& Choi, T.Y. (2015), 'Toward the Theory of the Supply Chain'. Journal of Supply Chain Management, 51 (2), 89-97.

- Christopher, M. and Towill, D.R. (2000), 'Supply Chain Migration from Lean and Functional to Agile and Customised,' Supply Chain Management: an International Journal, 5(4), 206-213.

- Cousins, P.D., Lawson, B. and Squire, B. (2006), 'Supply chain management: theory and practice - the emergence of an academic discipline?' International Journal of Operations \& Production Management, 26(7), 697-702.

- Croom, S., Romano, P. and Giannakis, M. (2000), 'Supply chain management: an analytical framework for critical literature review,' European Journal of Purchasing and Supply Management, 6(1), 67-83.

- CSCMP (2016), Council of Supply Chain Management Professionals, http://cscmp.org/about-us/supply-chain-management-definitions.

- Ellinger, A.E., Natarajarathinam, M., Adams, F.G., J.B., Gray, Hofman, D. and O’Marah, K. (2011), ‘Supply Chain Management Competency and Firm Financial Success', Journal of Business Logistics, 32(3), 214-226.

- Elmuti, D., Minnis, W. and Abebe, M. (2008), 'Longitudinal assessment of an integrated industrial supply chain', Supply Chain Management: an International Journal, 13(2), 151-159.

- Evangelista, P., Mogre, R., Perego, A., Raspagliesi, A. and Sweeney, E. (2012), 'A Survey Based Analysis of IT Adoption and 3PLs' Performance', Supply Chain Management: an International Journal, 17 (2), 172-186.

- Fawcett, S.E., Waller, M.A. and Bowersox, D.J. (2011), 'Cinderella in the CSuite: Conducting Influential Research to Advance the Logistics and Supply Chain Disciplines,' Journal of Business Logistics, 32(2), 115-121.

- Fawcett, S.E., and Waller, M.A. (2011), 'Making Sense Out of Chaos: Why Theory is Relevant to Supply Chain Research', Journal of Business Logistics, $32(1), 1-5$. 
- Fawcett, S.E., Magnan, G.M. and McCarter, M.W. (2008), 'Benefits, barriers, and bridges to effective supply chain management', Supply Chain Management: an International Journal, 13(1), 35-48.

- Grant, D.B. (2010), 'Using services marketing strategies for logistics customer service' in D. Waters (Ed.) Global Logistics: New Directions in Supply Chain Management ( $6^{\text {th }}$ Ed.), Kogan Page: London, 108-122.

- Grant, D.B. (2012), Logistics Management, Pearson Education: Harlow UK.

- Green Jr, K.W., Whitten, D. and Inman, R.A. (2008), 'The impact of logistics performance on organizational performance in a supply chain context, Supply Chain Management: an International Journal, 13(4), 317-327.

- Grimm, C., Knemeyer, M., Polyviou, M. and Ren, X. (2015), "Supply chain management research in management journals: a review of recent literature (20042013)", International Journal of Physical Distribution \& Logistics Management, 45(5), 404-458.

- Halldórsson, A., Hsuan, J. and Kotzab, H. (2015), 'Complementary theories to supply chain management revisited - from borrowing theories to theorizing,' Supply Chain Management: an International Journal, 20(6), 574-586.

- Halldórsson, A., Larson, P.D. and Poist, R.F. (2008), 'Supply chain management: a comparison of Scandinavian and American perspectives', International Journal of Physical Distribution \& Logistics Management, 38(2), 126-142.

- Jin, Y.H., Fawcett, A.M. and Fawcett, S.E. (2013), 'Awareness is not enough. Commitment and performance implications of supply chain integration', International Journal of Physical Distribution \& Logistics Management, 43(3), 205-230.

- Kathawala, Y and Abdou, K. (2003), 'Supply chain evaluation in the service industry: a framework development compared to manufacturing', Managerial Auditing Journal, 18(2), 140-149.

- Korpela, J., Lehmusvaara, A. and Tuominen, M. (2001), 'Customer servive based design of the supply chain', International Journal of Production Economics, 69(2), 192-204.

- Kotzab, H., Teller, C., Grant, D.B. and Sparks, L. (2011), 'Antecedents for the adoption and execution of supply chain management', Supply Chain Management: an International Journal, 16(4), 231-245. 
- Lambert, D. (1992), 'Developing a Customer-Focused Logistics Strategy', International Journal of Physical Distribution \& Logistics Management, 22(6), 12-19.

- Lambert, D.M. and Cooper, M.C. (2000), 'Issues in supply chain management', Industrial Marketing Management, 29(1), 65-83.

- Lambert, D.M. (2004), 'Supply Chain Management', in D.M. Lambert (ed.), Supply Chain Management: Processes, Partnerships, Performance, Sarasota, FL: Supply Chain Management Institute, 1-23.

- Lambert, D.M. and Stock, J.R. (1992), Strategic Logistics Management, London: Irwin Professional Publishing.

- Larson, P.D. and Halldórsson, A. (2004), 'Logistics versus Supply Chain Management: An International Survey', International Journal of Logistics: Research and Applications, 7(1), 17-31.

- Larson, P.D., Poist, R.F. and Halldórsson, A. (2007), 'Perspectives on logistics vs. SCM: a survey of SCM professionals', Journal of Business Logistics, 28(1), 1-24.

- Lummus, R. R., Krumwiede, D. W. and Vokurka, R. J. (2001), 'The Relationship of Logistics to Supply Chain Management: Developing a Common Industry Definition', Industrial Management and Data Systems, 101(8), 426-432.

- Mangan, J., Lalwani, C. and Gandner, B. (2004), 'Combining quantitative and qualitative methodologies in logistics research', International Journal of Physical Distribution \& Logistics Management 34(7), 565-78.

- Mangan J, Lalwani C, Butcher T, Javadpour R., Global Logistics and Supply Chain Management. Chichester: Wiley, 2012.

- Masters, J. M. and Pohlen, T. L. (1994), 'Evolution of the Logistics Profession', in Robeson, J. and Capacino, W. (eds.), The Logistics Handbook, New York: Free Press.

- Mentzer, J. T., DeWitt, W., Keebler, J. S., Min, S., Nix, N. W., Smith, C. D. and Zacharia Z. G. (2001), 'Defining Supply Chain Management', Journal of Business Logistics; 22(2), 1-25.

- Mentzer, J.T., Min, S. and Bobbitt, L.M. (2004), 'Towards a unified theory of logistics', International Journal of Physical Distribution \& Logistics Management, 34(8), 606-627. 
- New, S. (1997), 'The scope of supply chain management research', Supply Chain Management: an International Journal, 2(1), 15-22.

- Oliver, R. K. and Webber, M. D. (1982), 'Supply-Chain Management: Logistics Catches Up with Strategy', Outlook 31 (reprinted in: M. Christopher (ed.) (1992) Logistics: The Strategic Issues. Chapman and Hall, 63-75).

- Onwuegbuzie, A.J., Dickinson, W.B, Leech, N.L. and Zoran, A.G. (2009), 'A qualitative framework for collecting and analysing data in focus group research', International Journal of Qualitative Methods, 8(3), 1-21.

- Park, D. (2007), 'The Strategic Dimension of Supply Chain Management', Chapter 4 in E. Sweeney (ed.), Perspectives on Supply Chain Management and Logistics, Dublin: Blackhall.

- Porter, M.E. (1996), 'What is strategy?', Harvard Business Review, NovemberDecember, 61-78.

- Sandberg, E. and Abrahamsson, M. (2010), 'The role of top management in supply chain management practices', International Journal of Retail \& Distribution Management, 38(1), 57-69.

- Seuring, S. (2005), 'Case study research in supply chains - An outline and three examples' in Kotzab, H., Westhaus, M., Seuring, S.A., Muller, M. and Reiner, G. (eds.) Research Methodologies in Supply Chain Management, Heidelberg: Physica-Verlag, pp. 235-250.

- Stank, T.P., Dittmann, J.P., and Autry, C.W. (2011), 'The new supply chain agenda: a synopsis and directions for future research', International Journal of Physical Distribution \& Logistics Management, 41(10), 940-955.

- Stock, J.R. (1997), 'Applying theories from other disciplines to logistics', International Journal of Physical Distribution \& Logistics Management, 27(9/10), $515-539$.

- Stock, J.R. (2002), 'Marketing myopia revisited: Lessons for logistics', International Journal of Physical Distribution and Logistics Management, 32(1), $12-21$.

- Stock, J.R. and Boyer, S.L. (2009), 'Developing a consensus definition of supply chain management: a qualitative study', International Journal of Physical Distribution \& Logistics Management, 39(8), 690-711. 
- Stock, J.R., Boyer, S.L. and Harmon, T. (2010), 'Research opportunities in supply chain management', Journal of the Academy of Marketing Science, 38(1), 32-41.

- Storey, J, Emberson, C., Godsell, J and Harrison, A. (2006), 'Supply Chain Management: Theory, Practice and Future Challenges', International Journal of Operations \& Production Management, 26(7), 754-74.

- Sweeney, E. (2011), 'Towards a Unified Definition of Supply Chain Management. International Journal of Applied Logistics, 2(3), 30-48.

- Sweeney, E., Wagner, C. and Huber, B. (2008), 'Supply chain management diffusion among firms in the Republic of Ireland', International Journal of Logistics: Research and Applications, 11(4), 347-358.

- Sweeney, E, Grant, D.B. and Mangan, D.J. (2015), 'The implementation of supply chain management theory in practice: an empirical investigation', Supply Chain Management: an International Journal, 20(1), 56-70.

- Tan, K.C. (2001), 'A framework of supply chain management literature', European Journal of Purchasing and Supply Management, 7(1), 39-48.

- Tatham, P.H. and Kovacs, G. (2010), 'The impact of gender on humanitarian logistics', International Journal of Mass Emergencies \& Disasters, 28(2), 148169.

- Tokar, T. (2010), 'Behavioural research in logistics and supply chain management' The International Journal of Logistics Management, 21(1), 89-103.

- Trautrims, A., Grant, D.B. and Wong, C.Y. (2012), 'The interaction of human resources and managerial systems as they affect in-store replenishment operations,' Supply Chain Forum: An International Journal, 13(2), 56-66.

- Westbrook, R. and New, S. (2004), 'Postscript: Supply Chain Futures', Chapter 12 in Understanding Supply Chains (eds. Westbrook, R. and New, S.), Oxford: Oxford University Press.

- Zhang X., van Donk D.P. and van der Vaart T. (2011), 'Does ICT influence supply chain management and performance? A review of survey-based research', International Journal of Operations \& Production Management, 31(11), 12151247.

- Zinn, W and Goldsby. T.J. (2014), "Logistics Professional Identity: Strengthening the Discipline as Galaxies Collide," Journal of Business Logistics, 35(1), 23-28. 

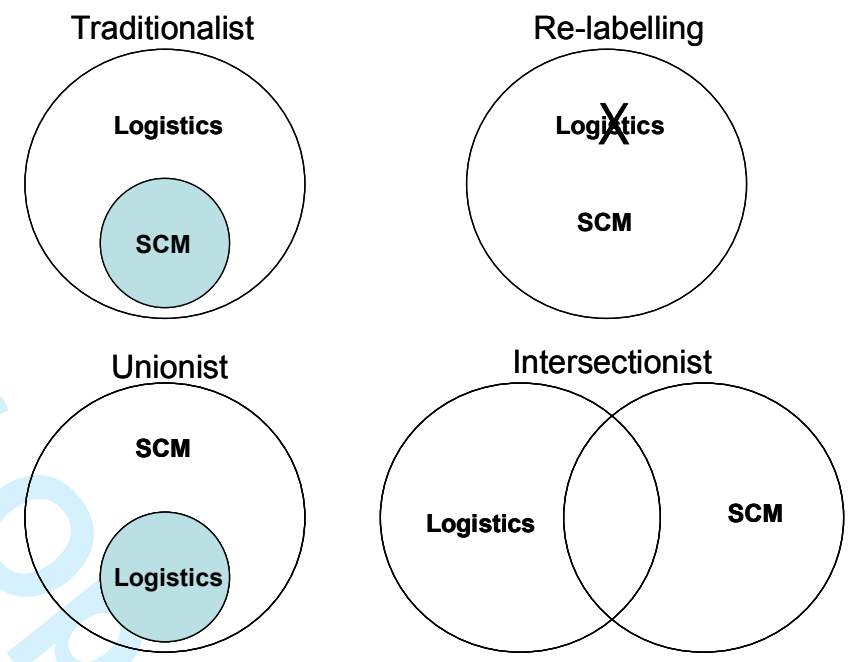

Figure 1: Perspectives on SCM versus Logistics

Source: Larson and Halldorsson (2004, p. 19)

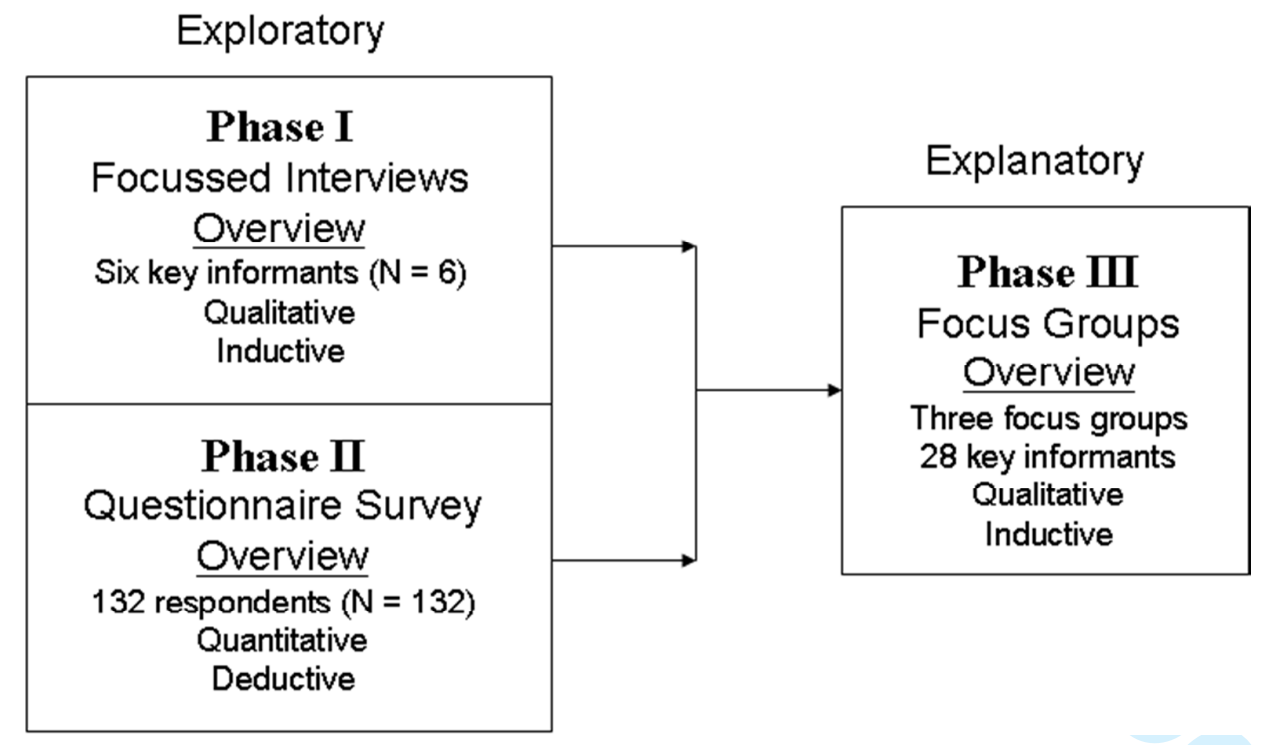

Figure 2: Overall Research Design 


\begin{tabular}{|c|c|}
\hline Informant & $\begin{array}{c}\text { Larson and Halldorsson } \\
\frac{(2004) \text { Logistics versus }}{\text { SCM Perspective }}\end{array}$ \\
\hline Manufacturer 1 & Unionist/Intersectionist \\
\hline Manufacturer 2 & Unionist \\
\hline 3PL/Distributor 1 & Intersectionist/Unionist \\
\hline 3PL/Distributor 2 & Unionist/Intersectionist \\
\hline Retailer 1 & Re-labelling \\
\hline Retailer 2 & Unionist/Intersectionist \\
\hline
\end{tabular}

Table 1: Focussed Interviews Responses and the Four Perspectives Model

\section{storage warehousing \\ origin traw material \\ supplier physicalservice \\ plan distribution activities \\ movement \\ transport \\ right customer flow \\ finished goods \\ management}

Figure 3: Words Used to Define "Logistics"

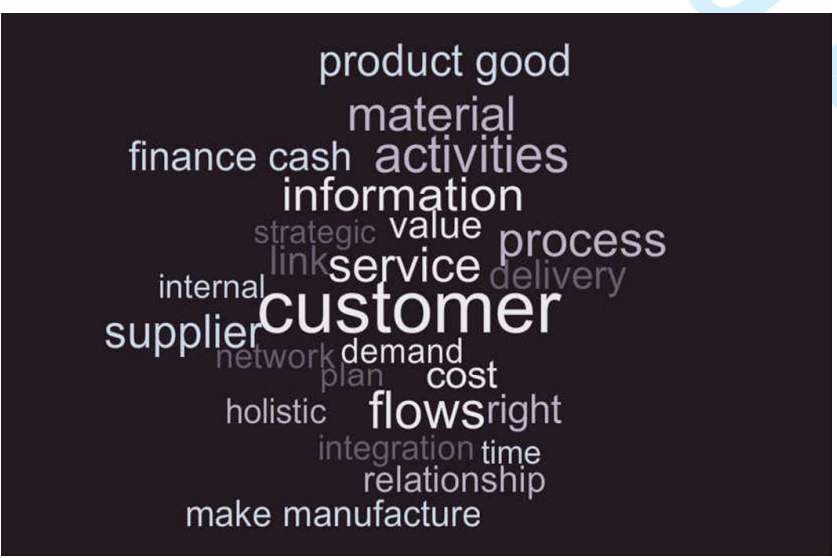

Figure 4: Words Used to Define "Supply Chain Management" 
Other $(2,3 \%)$

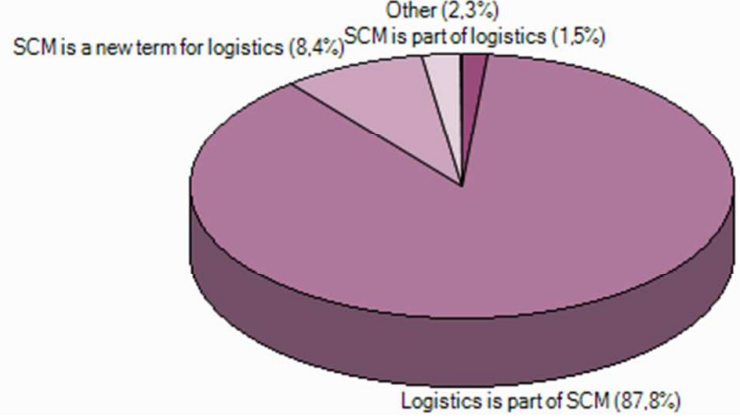

Figure 5: Relationship Between SCM and Logistics

4. Which of the following statements best describes the relationship between SCM and logistics? Which of the following best describes your professional background?

\begin{tabular}{|c|c|c|c|c|c|c|c|c|c|c|}
\hline & \multicolumn{2}{|c|}{$\begin{array}{c}\text { SCM is part of } \\
\text { logistics }\end{array}$} & \multicolumn{2}{|c|}{$\begin{array}{c}\text { Logistics is part of } \\
\text { SCM }\end{array}$} & \multicolumn{2}{|c|}{\begin{tabular}{c|} 
SCM is a new term \\
for logistics
\end{tabular}} & \multicolumn{2}{|c|}{ Other } & \multicolumn{2}{|c|}{ Total } \\
\hline & $\mathrm{N}$ & $\%$ cit. & $\mathrm{N}$ & $\%$ cit. & $\mathrm{N}$ & $\%$ cit. & $\mathrm{N}$ & $\%$ cit. & $\mathrm{N}$ & $\%$ cit. \\
\hline End-to-end supply chain management & 0 & $0.0 \%$ & 44 & $95.7 \%$ & 0 & $0.0 \%$ & 2 & $4.3 \%$ & 46 & $100.0 \%$ \\
\hline Purchasing (including supplier managemert) & 0 & $0.0 \%$ & 20 & $90.9 \%$ & 2 & $9.1 \%$ & 0 & $0.0 \%$ & 22 & $100.0 \%$ \\
\hline Production/operations management & 0 & $0.0 \%$ & 17 & $85.0 \%$ & 3 & $15.0 \%$ & 0 & $0.0 \%$ & 20 & $100.0 \%$ \\
\hline Transport management & 0 & $0.0 \%$ & 5 & $62.5 \%$ & 3 & $37.5 \%$ & 0 & $0.0 \%$ & 8 & $100.0 \%$ \\
\hline Warehouse management & $\mathbf{0}$ & $0.0 \%$ & 5 & $83.3 \%$ & 0 & $0.0 \%$ & 1 & $16.7 \%$ & 6 & $100.0 \%$ \\
\hline Customer service & 2 & $25.0 \%$ & 5 & $62.5 \%$ & 1 & $12.5 \%$ & 0 & $0.0 \%$ & 8 & $100.0 \%$ \\
\hline Other & $\mathbf{0}$ & $0.0 \%$ & 14 & $93.3 \%$ & 1 & $6.7 \%$ & 0 & $0.0 \%$ & 15 & $100.0 \%$ \\
\hline Total & 2 & $1.6 \%$ & 110 & $88.0 \%$ & 10 & $8.0 \%$ & 3 & $2.4 \%$ & 125 & \\
\hline
\end{tabular}

End-to-end supply chain management $195,7 \% 6$

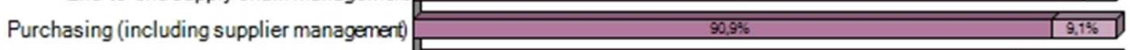

Production/operations management \begin{tabular}{|l|l|}
\hline $55 \% 6$ & $15 \% 6$ \\
\hline
\end{tabular}

Transport management \begin{tabular}{|l|l|}
\hline $62.5 \%$ & $37.5 \%$ \\
\hline
\end{tabular}

\begin{tabular}{|l|l|l|l|}
\hline Warehouse managemert & $18,7 \%$ \\
\hline
\end{tabular}

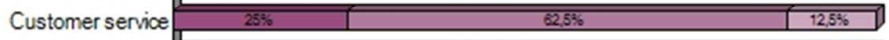

Other $993 \%$

Total $88 \% 6 \%$

$p=<0.1 \% ;$ chi2 $=52.77 ;$ dof $=18($ VS $)$

Dependence is highly significant.

Figure 6: Relationships Between SCM and Logistics by Respondent Background 
Figure 7: Types of Improvement Initiatives Implemented in the Last Two Years

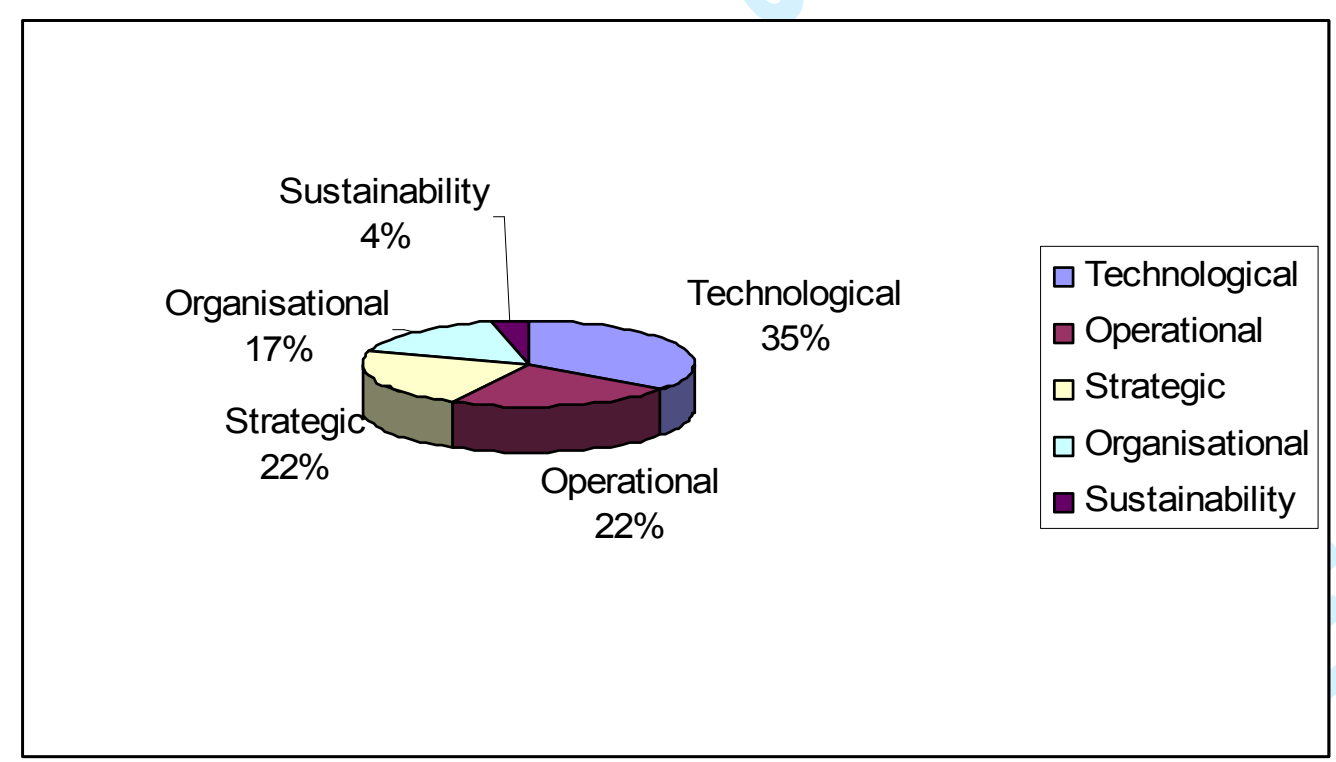

Figure 8: Types of Improvement Initiatives Planned in the Next Two Years 


\begin{tabular}{|c|c|c|c|}
\hline $\begin{array}{c}\text { Survey/ } \\
\text { Perspective }\end{array}$ & $\begin{array}{c}\text { US } \\
\text { (Larson et } \\
\text { al., 2007) }\end{array}$ & $\begin{array}{c}\text { Scandinavia } \\
\text { (Halldorosson } \\
\text { et al., 2008) }\end{array}$ & $\begin{array}{c}\text { Ireland } \\
\text { (Current } \\
\text { study, 2015) }\end{array}$ \\
\hline Traditionalist & 19 & 13 & 2 \\
\hline Re-labelling & 6 & 9 & 8 \\
\hline Unionist & 47 & 52 & 88 \\
\hline Intersectionist & 28 & 26 & 2 \\
\hline
\end{tabular}

Table 3: Percentage of Respondents by Perspective

\begin{tabular}{|c|c|c|c|}
\hline \multicolumn{2}{|c|}{ Empirical Research } & \multirow{2}{*}{$\begin{array}{l}\text { Critical Success Factor/ } \\
\text { Inhibitor of Success }\end{array}$} & \multirow{2}{*}{$\begin{array}{l}\text { Requirement } \\
\text { (Extant Literature) }\end{array}$} \\
\hline Exploratory & Explanatory & & \\
\hline Phase II & $\begin{array}{l}\text { FG1 } \\
\text { FG3 }\end{array}$ & $\begin{array}{l}\text { Strategic vs. tactical } \\
\text { focus in logistics and } \\
\text { SCM practice }\end{array}$ & $\begin{array}{l}\text { Cultural shift towards strategic focus } \\
\text { (Simchi-Levi and Kaminsky, 2003; van } \\
\text { Hoek and Harrison, 2004); senior } \\
\text { management responsibility (Fawcett et al., } \\
\text { 2011); pro-active approach (Sweeney, } \\
\text { 2008) }\end{array}$ \\
\hline $\begin{array}{l}\text { Phase I } \\
\text { Phase II }\end{array}$ & FG2 & $\begin{array}{l}\text { Common understanding } \\
\text { of SCM and its strategic } \\
\text { role }\end{array}$ & $\begin{array}{l}\text { Development of consensus definitions } \\
\text { (Mentzer et al., 2001; Stock and Boyer, } \\
2009 \text { ); integration and strategic } \\
\text { partnerships (Jin et al., 2013); supply } \\
\text { chain learning (Bessant et al. 2003) }\end{array}$ \\
\hline Phase II & FG1 & $\begin{array}{l}\text { Customer focus and } \\
\text { associated pull- } \\
\text { orientation }\end{array}$ & $\begin{array}{l}\text { Customer-driven networks (Bartels, 1982; } \\
\text { Stock, 2002); pull orientation (Grant, 2010; } \\
\text { Korpela et al., 2001); integration and } \\
\text { strategic partnerships (Jin et al., 2013) }\end{array}$ \\
\hline Phase I & $\begin{array}{l}\text { FG1 } \\
\text { FG3 }\end{array}$ & $\begin{array}{l}\text { Relative emphasis on } \\
\text { "hard-wiring" and "soft- } \\
\text { wiring" }\end{array}$ & $\begin{array}{l}\text { Recognition of role of people (Trautrims et } \\
\text { al., 2012; Storey et al., 2006); stronger } \\
\text { relationships (Tokar, 2010); education and } \\
\text { training (Fawcett et al., 2008) }\end{array}$ \\
\hline
\end{tabular}

Table 4: Critical Success Factors/Inhibitors to Success and Management

\section{Requirements}

